\title{
Force effects of the flow on energy absorbers in the presence of cavitation
}

\author{
Uktam Umurzakov ${ }^{1}$, Bakhtiyor Obidov ${ }^{1}$, Oybek Vokhidov ${ }^{1}$, Furqat Musulmanov ${ }^{2}$, Boyburi \\ Ashirov $^{3}$, and Javlon Suyunov ${ }^{4}$ \\ ${ }^{1}$ Tashkent Institute of Irrigation and Agricultural Mechanization Engineers, Tashkent, Uzbekistan \\ ${ }^{2}$ Bukhara Branch of the Tashkent Institute of Irrigation and Agricultural Mechanization Engineers, \\ Bukhara, Uzbekistan \\ ${ }^{3}$ Karshi Engineering-Economics Institute, Karshi, Uzbekistan \\ ${ }^{4}$ Samarkand State Architectural and Civil Engineering Institute, Samarkand, Uzbekistan
}

\begin{abstract}
As the experience of operating high-pressure spillway structures shows, the operating conditions of the downstream extinguishing devices are very difficult.

At flow rates, more than $12-15 \mathrm{~m} / \mathrm{s}$, downstream damping devices, as a rule, operate in a cavitation mode. First of all, this mode of operation gives rise to erosional destruction of the damper itself and the waters near it. This occurs where the cavitation torch closes on the structure.

Attempts to avoid these desirable phenomena by lining erosion sites with steel sheets do not always lead to the desired result since it is not uncommon for the steel lining to be torn off by hydrodynamic forces.

The separation of the cladding occurs in two cases: firstly, when the cladding is not in close contact with the concrete to be protected, and secondly, its anchoring is not enough. In both cases, fracture occurs from fatigue phenomena in the metal due to multiple oscillatory cycles from hydrodynamic loads.

It is difficult to avoid this in cavitation modes since the spectrum of pressure pulsations, in this case, is very wide, which leads to oscillations of linings at resonant frequencies. Apparently, the strength of the linings is an object of special research, and in the future, it should be dealt with theoretically and experimentally.

Hydrodynamic forces at high flow rates in the zone of intense energy extinguishing can reach such values that they can lift and overturn concrete slabs of water walls and water walls.

Currently, there are practically no specific and accounting for vertical hydrodynamic loads on slabs of water walls in the presence of cavitation on erosion-free absorbers in the technical literature.

To a certain degree of approximation, it is possible to use experimental data obtained on a model of the same structure but operating without cavitation, as data on hydrodynamic loads in the downstream of structures operating in a cavitation mode. The main disadvantage of such comparisons is that there is no guarantee that the amplitude and frequency characteristics of the flow during cavitation do not change (in particular, the amplitudes do not increase) as the cavitation limit is approached.
\end{abstract}




\section{Introduction}

\subsection{Discussion of the results based on the analysis of literature sources}

In [1], it is indicated that the comparison of pressure fluctuation standards obtained in kind under conditions of developed cavitation and on a model tested on a vacuum stand under simulated external pressure showed that when recalculating data from the model to nature, according to Froude, the relative value of the discrepancy between the comparative standards ripple does not exceed $9 \%$ [1-7].

Investigations of the model pressure pulsations at an unmodded external pressure showed that the standards of these pulsations, recalculated for nature according to Froude, are underestimated (by about 2.5 times) in comparison with the field values obtained during cavitation. The largest relative discrepancy between these data was $63 \%$ [1]. In addition, it can be noted that under cavitation modes, other important flow characteristics also change, such as the weir discharge coefficients, the drag coefficients of the dampers, and the pattern of the water flow around the body [8-14]. Figure 1 shows a graph [21] illustrating changes in the weir discharge coefficient versus the cavitation number $K$ and $H / a$.

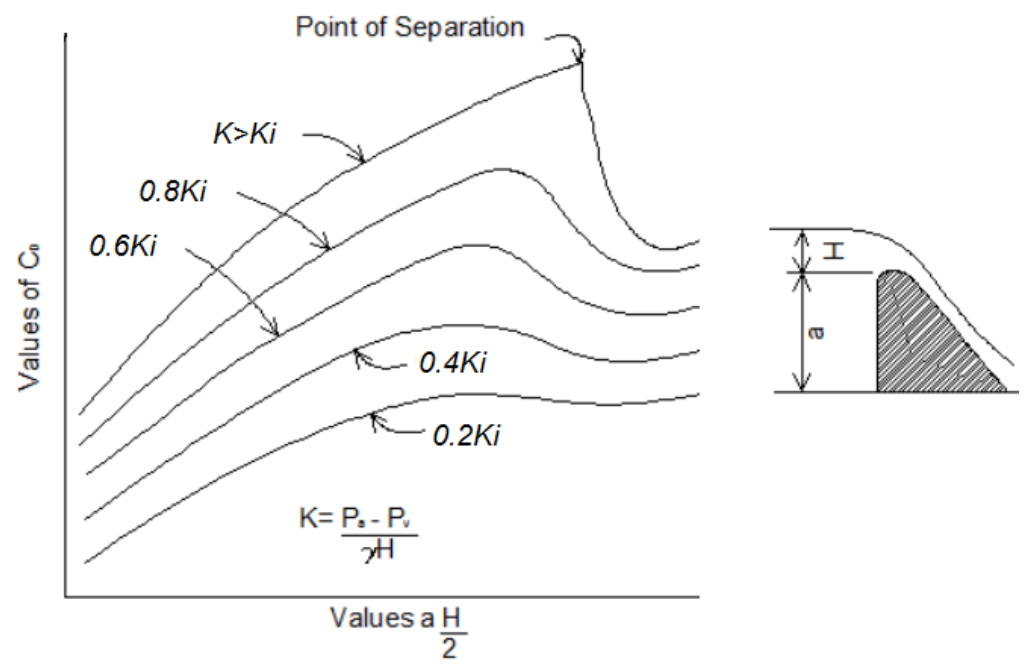

Fig. 1. Graphs of the dependence of the weir flow rate on the cavitation number $K$ and $H / a$

The given factual material makes it possible to assert that to correctly take into account hydrodynamic loads during cavitation, the models of the investigated structures should also be tested in the cavitation mode. Such a direct way to achieve the indicated modes, such as increasing the flow rate on the model, does not solve the problem since the linear scales of the structure modeling are not observed (the main thing is that the hydraulic jump is not modeled) [15-20].

The most expedient for studying the hydrodynamic characteristics of cavitating flows is to research vacuum cavitation stands. They make it possible to study the quantitative characteristics of a structure at various stages of developing cavitation processes on it.

As the experience of operating real structures with heads of 20-30 m and more shows, it is either impossible to exclude cavitation phenomena on damping devices, or rather complex engineering measures are required.

Therefore, there is a desire to go on the assumption of the degree of development of cavitation with the use of erosion-free structures. 
Such a proposal can be found in the works of N.P. Rozanov [20, 21]. The principle of non-erosion energy absorbers is that at various stages of cavitation, the zones of formation of decay of cavitation plumes do not have direct contact with solid boundaries of the flow.

Experience also well confirms that the separation of the solid boundary from the torch, for example, the deepening of the bottom immediately behind the ledge, and so on, sharply reduces the intensity of cavitation erosion or completely eliminates it.

The decay of cavitation bubbles occurs in this case inside the flow at such a distance from its solid boundary that this decay does not have a harmful erosion effect on it. In such cases, we do not get any clearly pronounced zones of intense erosion at any values $\beta$. Separated flow around the elements of hydraulic structures, which have a form that ensures the removal of cavitation cavities from the surface of the structure into the flow at all stages of cavitation, can be used without the possibility of dangerous damage. Since the experience of using erosion-free structures is not large, when using them, a certain caution must be observed, using a sufficiently cavitation-resistant material in the cavitation zone. [20].

Energy absorbers made taking into account the above are called erosion-free [21]. At present, erosion-free dampers are still poorly understood. At the same time, some recommendations were developed for the selection of their shape and the values of $K_{c r}$ and $C$ were obtained. Judging by these recommendations, erosion-free dampers are promising for high-pressure structures.

This circumstance and the lack of study of the issue of hydrodynamic loads downstream in the presence of cavitation determine the directions of research in this work.

\section{Methods}

\subsection{Vacuum unit, models, and similarity criteria}

To reproduce cavitation and study its effect on the elements of hydraulic structures, cavitation units are used. According to the principle of their operation, these installations can be subdivided into several groups: acoustic rotary and magnetostrictive installations, jet-impact vacuum stands, hydrodynamic tubes [22, 23]. In hydraulic engineering, hydrodynamic tubes and vacuum benches are mainly used.

To obtain data on the conditions of occurrence, development, and impact of a cavitating flow on the elements of spillway hydraulic structures, vacuum stands are used. Their main advantage is that they allow the creation of cavitation conditions on models that meet the Froude similarity criterion.

Studies of the force effects of the flow in the presence of cavitation were carried out in the vacuum test bench of the laboratory of hydraulic structures Moscow State Irrigation and Reclamation Institute.

The vacuum unit makes it possible to conduct cavitation studies of the elements of hydraulic structures in the presence of a free flow surface. The rather large dimensions of the installation provide for the conduct of cavitation studies of flat and half-space models of sufficiently large dimensions, with direct observation of cavitation on absorbers located in a hydraulic jump.

The vacuum cavitation stand is a sealed tray, the working part of which is equipped with viewing windows in the model installation area. The chute is $0.6 \mathrm{~m}$ wide, $2 \mathrm{~m}$ high at the head, and $0.9 \mathrm{~m}$ high at the end, with a total length of $8.4 \mathrm{~m}$.

The water supply system to the installation is closed. With the help of a $12 \mathrm{nDs}$ pump, it is possible to provide a flow rate in the stand up to $2501 / \mathrm{s}$ at various fillings with flow rates in the working section up to $10 \mathrm{~m} / \mathrm{s}$. 
To avoid cavitation of the pumps, as well as air leakage through them, the latter are located $9 \mathrm{~m}$ below the level of the working chamber.

This allows the hydrostatic pressure to compensate for the vacuum and prevent pump cavitation. At the end of the horizontal flume, there is a vertical shaft that acts as a reservoir, which contributes to the stable operation of the pump. The flow rate supplied to the stand is regulated by a gate valve, as well as by shunts, along which medium and small gate valves are installed. With the help of powerful vacuum pumps (VVN-12 and 6 pumps RVN-12), the unit can create a vacuum of up to 9.5-9.8 m. In addition, the stand is equipped with some instruments that control the mode of its operation in frequency, an exemplary vacuum gauge with a scale division of $0.01 \mathrm{~atm}$., a mercury differential flow meter, and piezometers with vacuum compensation, as well as ultrasonic equipment.

It is known that when simulating the operation of energy absorbers in downstream in the presence, as in the presence of cavitation, it is necessary to comply with the Froude similarity criterion $(\mathrm{Fr}=$ idem $)$ and conduct research in the self-similar region at Reynolds numbers $R e_{m}>R e_{g r}$.

The experiments were carried out with Froude numbers calculated for a compressed section $\mathrm{Fr}_{1}=16-64$ and Reynolds number $\mathrm{Re}_{1}=4 * 10^{5}-1.1 * 10^{6}$.

To observe the approximate similarity of cavitation phenomena, it is necessary to fulfill the following conditions:

$$
K_{n}=\eta K_{m}
$$

where: $K_{n}$ and $K_{m}$ are parameters of cavitation for nature and model; $\eta$ is model scale correction factor (was accepted $\eta-1.0$ given the large scale of the model, $R e_{m}>10^{5}-$ $10^{6}$.

The absence of cavitation will be ensured provided

$$
K>K_{c r}
$$

The cavitation parameter is usually written as follows:

$$
K=\frac{H_{\text {har }}-H_{c r}}{v_{\text {har }}^{2} / 2 g}
$$

where: $H_{h a r}=H_{a}+h\left(H_{a}\right.$ is pressure created above a free surface in a cavitation unit, m.w.st, for nature - atmospheric pressure); $h$ is the height of the water column under the damper m.v.st.; $v_{\text {har }}$ is characteristic flow speed (taken from the diagram of the distribution of velocities at the level of the top of the damper), $\mathrm{m} / \mathrm{s} ; g$ is free fall acceleration, $\mathrm{m} / \mathrm{s}^{2} ; H_{c r}$ is pressure (m.v.st.) парообразования vaporization (taken as for pure water).

In experiments, cavitation in its various stages was created by adjusting the vacuum.

The hydraulic jump in the installation was created when water flowed out from under the shutter with a sharp edge.

The fragmentary model was a pond with two rows of damping devices: in the first row erosion-free dampers, in the second - a pond.

In this work, a water column with erosion-free dampers was investigated (four dampers were studied in figure 2). 


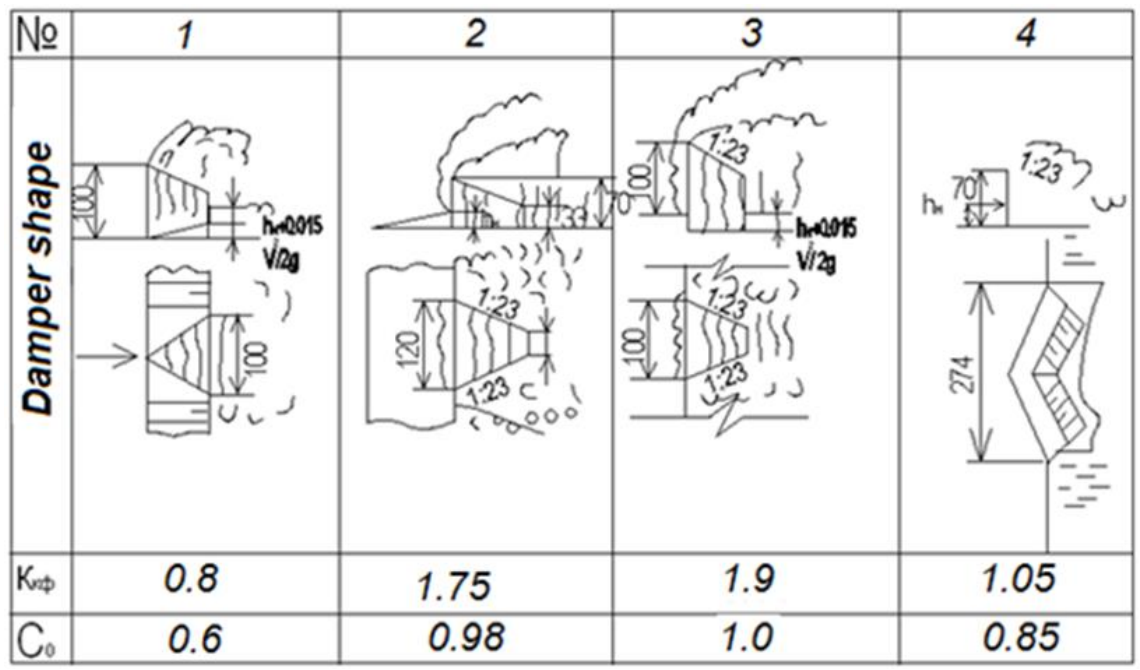

Fig. 2. Study of the shape of model erosion-free energy absorbers (dimensions in $\mathrm{mm}$ )

In the work, the experiments provided the determination of the total hydrodynamic load on the entire mounting plates.

In the studies, a sensor plate was used to measure the total vertical and moment loads in the longitudinal and transverse directions.

\section{Results and discussion}

\section{Results of cavitation studies}

Modern methods of mathematical processing of statistical experimental data make it possible to calculate the total hydrodynamic loads on the slabs of the reservoir under the condition. There are known pressure pulsations at several points and their correlation dependences.

The reliability of this method cannot be considered satisfactory because it uses not functional dependencies but correlation ones, which have their own degree of reliability.

Therefore, the main method for studying hydrodynamic loads on structures such as slabs of a water face at present, apparently, should be considered a direct measurement of hydrodynamic loads, not the area. Such experiments were carried out by us using an area sensor.

Integral pulsation loads were studied by us depending on the development of cavitation of the slab's dimensions. In figures 3 and 4 show the average values of specific pulsation loads and loads equivalent to the impact of overturning moments, depending on the stage of cavitation $(\beta)$ for erosion-free types of absorbers [24-26]. 


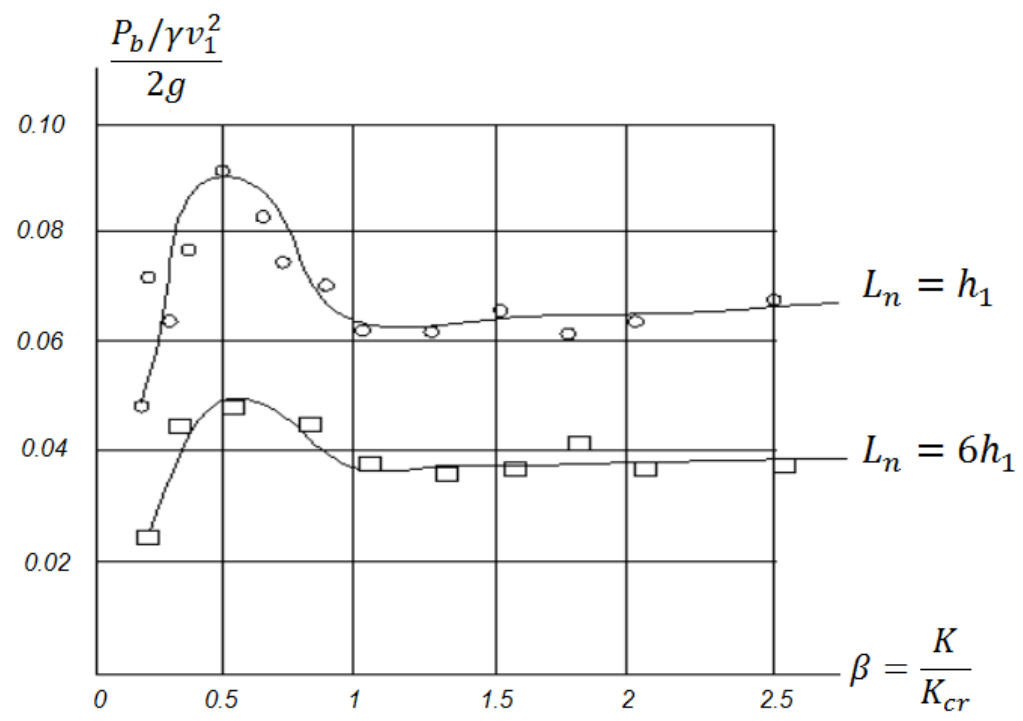

Fig.3. Influence of the cavitation stage $(\beta)$ on the standards of specific pulsation loads for absorbers № 2 , № 3

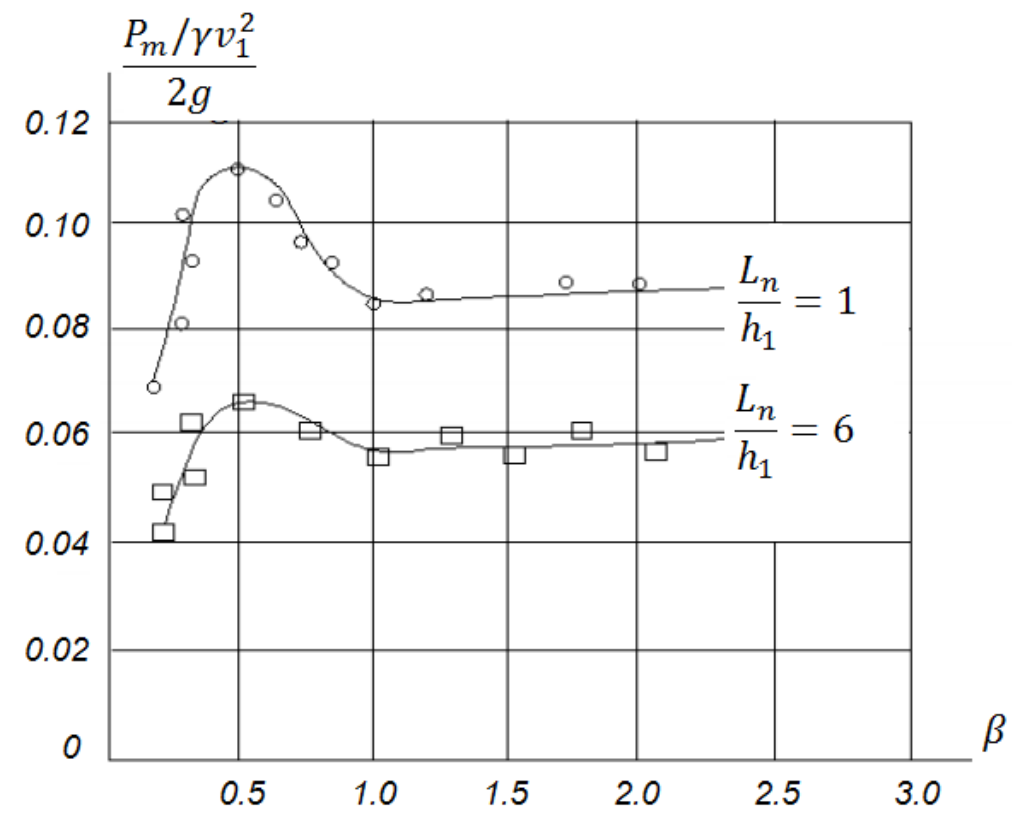

Fig. 4. Influence of the cavitation stage $(\beta)$ on the standard of specific pulsation loads equivalent to the action of the overturning moment for absorbers № 2, № 3

It should be noted that the nature of the change in the standards of specific pulsation loads and moments on the plate, depending on the stage of cavitation, is similar to that obtained using a point sensor, although the amplitudes of the pulsation standards due to their averaging are much lower than Figure 5. 

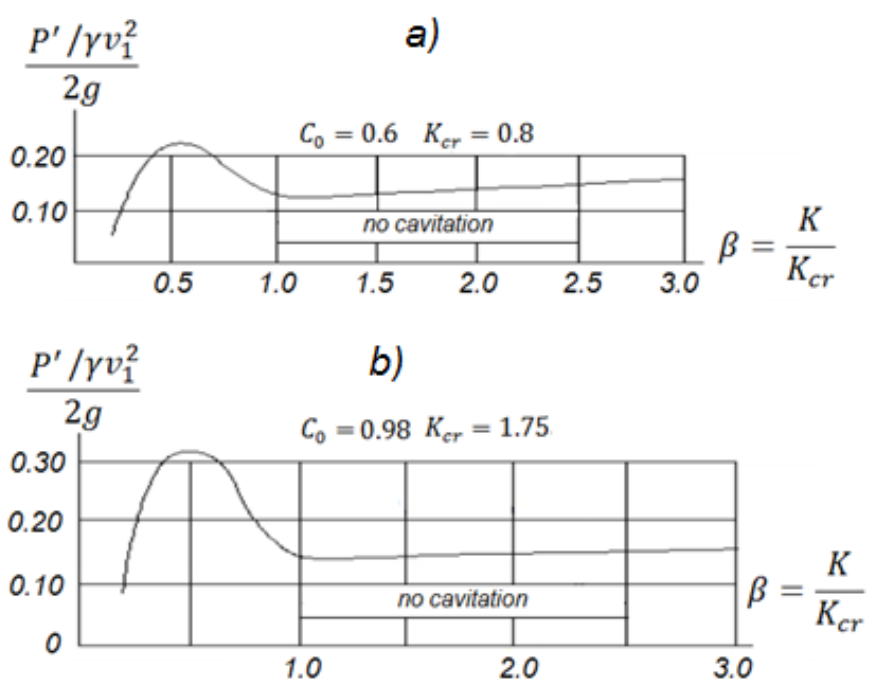

Fig. 5. Graphs of changes in the intensity of the pressure pulsation behind the energy dampers in the water wall zone of the highest pulsation pressure, depending on the cavitation stage $a$ ) for the damper№ $1 ; b$ ) for the damper № 2

From Figures 3 and 4, it can be seen that with the length of the slab $L_{n}=6 h_{1}$ to more, in cavitation-free mode $(\beta \geq 1.0)$, ripple load standards are constant.

With a decrease in $\beta$ to 0.5 (advanced stage of cavitation), these standards grow and take maximum values: load pulsation standard $P_{m}^{\prime} / \gamma v_{1}^{2} / 2 g=0.05$, standard for specific ripple load equivalent to overturning moment action $P_{m}^{\prime} / \gamma v_{1}^{2} / 2 g=0.065$.

In the considered cases, the values of the distributed ripple load equivalent to the overturning moment $P_{m}^{\prime}$, more ripple loads $P_{v}^{\prime}$. The materials presented in this article show some importance when considering the hydrodynamic loads acting on the slabs of the reservoir. Compare the values of loads that can occur in the presence of cavitation and - in its absence.

Using the obtained dependencies, it is possible to predict the total loads on the downstream attachment elements and evaluate the effect of cavitation on them.

\section{Conclusions}

1. Experiments have shown that the standard of the area-averaged load, as well as the pressure pulsations at individual points, in the process of the development of cavitation, passes through a maximum, which is observed in the developed stage of cavitation $\left(\beta=\beta_{0} \approx 0.5\right)$.

2. For slabs of size $L=h_{1}$ and $L=6 h_{1}$, located on a pond with cavitating erosion-free dampers, universal graphs have been developed to determine the average pulsation load and overturning moment as cavitation develops. The graphs show that the values of the ripple moments $\left(P_{m}^{\prime}\right)$ are greater than the ripple loads $\left(P_{v}^{\prime}\right)$ by about $0.03 \cdot \frac{\gamma v_{1}^{2}}{2 g}$. This circumstance suggests that when calculating the fixing of a water stand for stability, it is necessary to take into account the pulsation moments.

3. Specific ripple load on slabs with dimensions $L_{n}=(1 \div 6) h_{1}$, can be determined by graphical dependencies. With an increase in the size of the slabs, the total pulsation loads decrease in lengths more than $6 h_{1}$, the decrease practically stops. In this 
cavitation-free mode, the pulsation loads in comparison with point pulsations decreased by 2 - 3 times, and in the developed stage of cavitation by 3 - 5 times.

4. For a pond with erosion-free dampers, graphical dependences of the averaging coefficient have been developed for the transition from pressure pulsation at a point to pulsating loads on slabs of different sizes at different stages of cavitation. The averaging coefficients of the overturning moment $K_{0 \mathrm{M}}^{\prime}$ are on average $35 \%$ higher than the values of $K_{0}^{\prime}$ for the vertical load.

\section{References}

1. Obidov B., Vokhidov O., Tadjieva D., Kurbanova, U., Isakov A. Hydrodynamic effects on the flow elements of the downstream devices in the presence of cavitation. IOP Conf. Ser. Mater. Sci. Eng. 1030, 012114 (2021).

2. Bazarov D., Vatin N., Obidov B., and Vokhidov O. Hydrodynamic effects of the flow on the slab of the stand in the presence of cavitation. IOP Conf. Ser. Mater. Sci. Eng. 1030, 012110 (2021).

3. Bazarov D. and Vokhidov O. Extinguishing Excess Flow Energy in Spillway Structures. In book: Proceedings of EECE 2020, LNCE 150, pp. 535-545, (2021) DOI: $10.1007 / 978-3-030-72404-752$

4. Bazarov D., Norkulov B., Vokhidov O., Uljaev F., Ishankulov, Z. Two-dimensional flow movement in the area of protective regulatory structures. IOP Conf. Ser. Mater. Sci. Eng. 890, 012162 (2020)

5. Chernykh O.N. Hydrodynamic loads and stability of the downstream fastening of hydraulic structures. Power Technol. Eng. 24., (1983)

6. Tsvetkov P.K. To the calculation of a hydraulic jump in an expanding channel Proc. Inst. Hydrol., pp. 79-93, (1952)

7. Krutov A., Norkulov B., Uljaev F., and Jamalov F. Results of a numerical study of currents in the vicinity of a damless water intake. IOP Conf. Ser. Mater. Sci. Eng. 1030, 012121 (2021).

8. Krutov A., Norkulov B., Mavlyanova D. Simulation of spreading of non-conservative passive substances in water bodies. IOP Conf. Ser. Mater. Sci. Eng. 883(1), 012028 (2020)

9. Krutov A., Choriev R., Norkulov B., Mavlyanova D. and Shomurodov A. Mathematical modelling of bottom deformations in the kinematic wave approximation. IOP Conf. Ser. Mater. Sci. Eng. 1030, 012147 (2021).

10. Bazarov D., Markova I., Sultanov S. and Kattakulov F. Dynamics of the hydraulic and alluvial regime of the lower reaches of the Amudarya after the commissioning of the Takhiatash and Tuyamuyun hydrosystems. IOP Conf. Ser. Mater. Sci. Eng. 1030, 012110 (2021).

11. Ivanov V.M. Improving the theory and methods of calculation hydrodynamic effects on spillway structures. (2004)

12. Wilson E.H. Boundary layer effects on hydraulic jump location Hydraul. Div. pp.1126-1136, (1972)

13. Arndt R.E.A. Cavitation in fluid machinery and hydraulic structures. Annu. Rev. Fluid Mech. 13. pp. 274-328. (1981)

14. Altimira M., Fuchs L. Numerical investigation of throttle flow under cavitating conditions, International Journal of Multiphase Flow. 75, pp. 124-136, (2015)

15. Amromin E. Determination of Cavity Detachment for Sheet Cavitation, Journal of Fluids Engineering, 129, pp. 1105-1111, (2007)

16. Amromin E., Kopriva J., Arndt R.E.A., Wosnik M. Hydrofoil Drag Reduction by Partial Cavitation // Journal of Fluids Engineering. 128, pp. 931-936, (2006) 
17. Rybakov V., Jos V., Raimova I., and Kudryavtsev K. Modal analysis of frameless arches made of thin-walled steel profiles. IOP Conf. Ser. Mater. Sci. Eng. 883, (2020).

18. Bazarov D., Markova I., Raimova I., Sultanov Sh. Water flow motion in the vehicle of main channels. IOP Conf. Ser. Mater. Sci. Eng. 883, 012025 (2020).

19. Uralov B., Rakhmatov N., Khidirov S., Uljaev F., Raimova I. Hydraulic modes of damless water intake. IOP Conf. Ser. Mater. Sci. Eng. 1030(1), 012123 (2021)

20. Rozanova N.N. Issledovaniye gasheniya energii v vysokonapornykh vodosbrosakh $\mathrm{v}$ usloviyakh propuska zakruchennykh potokov i pri kavitatsii. (1979).

21. Obidov B.M. Gidrodinamicheskiye vozdeystviya potoka na elementy ustroystv nizhnego b'yefa pri nalichii kavitatsii na bezerozionnykh gasitelyakh. (1985).

22. Obidov B., Choriev R., Vokhidov O. and Rajabov M. Experimental studies of horizontal flow effects in the presence of cavitation on erosion - free dampers. IOP Conf. Ser. Mater. Sci. Eng. 883, 012051 (2020).

23. Obidov B., Vokhidov O., Shodiev B., Ashirov B. and Sapaeva M. Hydrodynamic loads on a water drain with cavitation quenchers. IOP Conf. Ser. Mater. Sci. Eng. 883, 012011 (2020).

24. Krutov A., Norkulov B., Artikbekova F., Nurmatov P. Optimal location of an intake at a reservoir prone to salt diffusion. IOP Conf. Ser. Mater. Sci. Eng. 869(7), 072020, (2020)

25. Eshev S., Latipov S., Qurbonov A., Berdiev M., Mamatov N. Non-eroding speed of water flow of channels running in cohesive soils. IOP Conf. Ser. Mater. Sci. Eng. 1030, 012131 (2021).

26. Eshev S., Rakhimov A., Gayimnazarov I., Shodiev B., Bobomurodov F. Dynamically stable sections of large soil canals taking into account wind waves. IOP Conf. Ser. Mater. Sci. Eng. 1030, 012134 (2021). 